Review

\title{
Rental Estimation of Reverse Mortgages (RM): The Case of Home as Rental in Retirement
}

\author{
${ }^{1}$ Gurudeo Anand Tularam and ${ }^{2}$ Ali Abdullah Al Ibrahim \\ ${ }^{I}$ Department of Mathematics and Statistics Griffith Sciences, \\ [ENV, EFRI] Griffith University, Nathan Australia \\ ${ }^{2}$ Department of Studies and Research, Kingdom of Saudi Arabia (KSA), Saudi Arabia
}

Article history

Received: 30-09-2017

Revised: 06-11-2017

Accepted: 5-01-2018

Corresponding Author: Gurudeo Anand Tularam Department of Mathematics and Statistics Griffith Sciences, [ENV, EFRI] Griffith University, Nathan Australia Email: a.tularam20@gmail.com

\begin{abstract}
The aim of this paper was to compare the rental market conditions in retirement with an RM contract that involves a retiree's home and its valuation. It is noted that the current rental market conditions are to be examined thoroughly before any engagement in RM is to be instituted. The rental value per week for 1, 2-Bedroom Units and 3 or more Bedroom homes are to study in some depth. The availability of rental housing should also be studied to determine whether it is indeed possible to obtain secure longer term rental housing for the retired persons. In this study only a certain group has been investigated and further work is necessary if RM is to be a major contract that retired persons may engage in thus achieving a better quality of life after retirement given the many years of service couples have given to their country. The lack of engagement in Australia is a two way story in that the less than usual interest of retiree's on RM is met by the banks very low level of advertising of the same. The lack of information has created a lack of trust in RM; the thought of letting someone else own apart of one's home towards the later part of one's life in some manner is not well accepted or understood given the retiree's home is mostly a mortgage free asset. The modelling and analyses conducted in this study show that the return in terms of rental is well in competition with the existing rental market in Australia and in particular when using the largest city data from Sydney and other rental markets.
\end{abstract}

Keywords: Rental Housing Market, Reverse Mortgages, Retired Persons, Comparative Analysis

\section{Introduction}

The financial instrument which provides a vehicle of conversion of home equity into cash is mostly referred to as a Reverse mortgage (Edward et al., 2007; Nance, 2016). The process allows mostly the elderly to use the equity in their home to borrow funds when needed (Bridge et al., 2010). So the homeowner converts their equity into cash to remain or stay at the property as long as they please after a certain age say 62 for example. The house is in essence enabling the lender to rent back from the borrower. Essentially, then a reverse mortgage is to borrow against the value of the owner's property (Nance, 2016; Warshawsky, 2017; Warshawsky and Zohrabyan, 2016). One of the possible borrowings (as described in the next section) is that the homeowner receives a monthly amount over the time of the so called loan in reverse; essentially then this is an annuity, based on the value of his property (Bridge et al., 2010; Nance, 2016). The reverse mortgaged amount in then terminate with accumulated interest until the due date or the death of the owner, at which time the lender may sell the property to obtain the smaller of the debt incurred or the net value of the property. The remaining value of the property is passed onto the deceased's estate (Liang et al., 2008).

There two main issues that concern the borrower and the lender in this reverse mortgage game plan. (i) a growing economy grows leads to higher property values over the years thus the homeowner/borrower will have a more valuable asset against which he/she can continue to utilize the excess home equity; (ii) there could also be a benefit to the lender in that with appreciating property values over time would reduce the chance of the total debt exceeding the property valuation at the conclusion or termination time (Firman, 2015). 
There are many countries now who are particularly investigating the concept of reverse mortgage such as Singapore (Cho et al., 2013). The situation is similar in the US and UK where the concept of reverse mortgages is gaining acceptance (Chen et al., 2010). The Singapore government is concerned with their ageing population as the percentage of the elderly population grows in numbers. Just as in the US and UK, there is now a concern regarding the elderly's comfortability of living given that they generally have much equity tied up in their home. As such the concept of reverse mortgages among countries that continue to have a growing number in the group of elderly population is gaining acceptance and growing; such as Australia (Reed, 2009).

\section{Background to Reverse Mortgage (RM)}

In developed countries growing proportion of elderly in the communities are finding that the regular income from savings and/or pensions are usually insufficient for a comfortable level of living life, yet most elderly live in houses which are almost free of mortgages (Firman, 2015). The most important aspect is that most of the elderly who are in such a situation would not prefer to sell their houses and then move to another environment either downsizing or into care communities for example, until they are unable to totally take care of themselves (Thomas, 2014a; 2014b).

In response of this aspect of financial demand, the financial agencies and markets in many counties have developed financial products to provide benefits needed in retirement but also to help to manage the associated risks involved (Maestas and Zissimopoulos, 2010). There are many financial products but there are two main kinds of products now available to support the elderly and these are called Reverse Mortgages (RM) and Home Reversions (HR) (Alai et al., 2014). By far the most common is the Reverse Mortgages (RM). The major attraction of RM is that the borrower makes no payments until the RM is terminated; either by death of the borrower or the borrower moving out of home or selling the home. The ownership is retained by the homeowner throughout therefore the owner may choose to sell the house at a time but then the seller/s must pay the total debts incurred in RM to that time. Reverse mortgages can also be issued couples and such cases the lender uses the age of the younger of the couple for mortgage consideration (Nakajima, 2014a; 2014b).

As the borrowing in Reverse Mortgage is based on the equity of the borrower's house, there is the risk that the value of the house at termination is insufficient to cover the liability and when this occurs lender may not have recourse to other avenues to extract funds. The RM with such non-recourse guarantee for the shortfall are said to have No Negative Equity Guarantee (NNEG). In particular US RM's are administered by the Housing and Urban Development (HUD) and the NNEG and any shortfall of funds at the termination are covered by the
Federal Government. Some qualitative and quantitate description about in relation to Reverse Mortgages in US are available in Nakajima (2012). In other countries, the lender may likely accommodate the value or risk related to NNEG within the RM design.

The main aim of this paper is to examine the concept of free rental in Reverse Mortgages and how this is incorporated into the NNEG component. Essentially, the goal here is to estimate the free rental value of the program given the known parameters in RM.

Generally, those who undertake Reverse Mortgage are usually over 60 (62 in US); and the borrowing is generally limited to a fraction of the appraised value of the house at the time of borrowing. In many cases, the owners lack the mathematics of the financial calculations involved (Hopf and Tularam, 2014; Tularam, 2013). However, the borrower can choose one of the six possible alternatives within the program:

1. A lump-sum: Borrower receives a single lump-sum payment

2. Tenure: borrower receives a fixed periodic payment as long as at least one of the borrowers continue to live in the same house

3. Term: Borrower receives a fixed payment for a fixed length of time

4. Line of Credit (LOC): Borrower can flexibly draw cash, up to a limit, during a predetermined drawing period

5. Modified tenure: Combination of tenure and LOC

6. Modified term: Combination of term and LOC

Whatever the type of borrowing, the lender will charge an initial and regular premiums to mitigate the risks of NNEG and/or some failure of the program but the borrower stays in the home free of any rental until the termination due to death or moving out of the house. The borrower has to incur all maintenance expenses for the property until the policy termination

\section{Modelling RM using Lump Sum Model Using Continual Time Case}

Consider a retired individual who takes out a reverse mortgage loan amount of $A_{0}$ dollars, against his house currently valued at $\mathrm{H}_{0}$ dollars. If at time $t$ the loan amount is $A_{t}$, the house price is $H_{t}$ and the cost of the capital is $C_{t}$, then the value of the reverse mortgage loan is labelled $V_{t}$, which is equal to $\min \left(A_{t}, H_{t}\right)$. In this manner, the loss to the lender given as $L_{t}$ is: $L_{t}=C_{t}-V_{t}=C_{t}-\min \left(A_{t}, H_{t}\right)$.

If the loan amount $A_{t}$ accumulates at a risk free interest rate of $r_{t}$ plus a risk premium rate of $\lambda$, while house price $H_{t}$ appreciates at a rate of $\delta_{t}$; and the cost of the capital $C_{t}$ accumulates at an interest rate of $\gamma$, then the loan value process can be given as:

$$
A_{t=} A_{0} \exp \left(\int_{0}^{t}\left(r_{s}+\lambda\right) \mathrm{ds}\right),
$$


and the house price process is:

$$
H_{t}=H_{0} \exp \left(\int_{0}^{t}\left(\delta_{s}\right) \mathrm{ds}\right),
$$

and the cost of capital process is given by:

$$
C_{t}=A_{0} \exp \left(\int_{0}^{t}\left(\gamma_{s}\right) \mathrm{ds}\right) .
$$

Since the value of the loan repayment $V_{t}$ is the smaller of the house price and the accumulated loan amount, we have:

$$
V_{t}=\min \left(A_{0} \exp \left(\int_{0}^{t}\left(r_{s}+\lambda\right) \mathrm{ds}\right), H_{0} \exp \left(\int_{0}^{t}\left(\delta_{s}\right) \mathrm{ds}\right)\right) .
$$

The loss to the lender $L_{t}$ at time $t$ can be given as:

$$
L_{t}=A_{0} \exp \left(\int_{0}^{t}\left(\gamma_{s}\right) \mathrm{ds}\right)-\min \left[\begin{array}{l}
A_{0} \exp \left(\int_{0}^{t}\left(r_{s}+\lambda\right) \mathrm{ds}\right), \\
H_{0} \exp \left(\int_{0}^{t}\left(\delta_{s}\right) \mathrm{ds}\right)
\end{array}\right] .
$$

The time of the reverse mortgage loan is a random variable $T$; which is the future remaining lifetime of the borrower. At settlement the loss $L_{T}$ to the lender can be expressed as the random variable:

$$
L_{T}=A_{0} \exp \left(\int_{0}^{T}\left(\gamma_{s}\right) \mathrm{ds}\right)-\min \left[\begin{array}{l}
A_{0} \exp \left(\int_{0}^{T}\left(r_{s}+\lambda\right) \mathrm{ds}\right) \\
H_{0} \exp \left(\int_{0}^{T}\left(\delta_{s}\right) \mathrm{ds}\right)
\end{array}\right] .
$$

Using the actuarial equivalence principle that states that the present value of total expected gain ought to be the same value as the present value of total expected loss; therefore we can state: $E\left[e^{-r T} L_{T}\right]=0$.

Using this fact, the pricing equation for the reverse mortgage can be written as follows:

$$
\text { If } E\left[e^{-r T} L_{T}\right]=0 \text { then: }
$$$$
E\left[A_{0} \exp \left(\int_{0}^{T}\left(\gamma_{s}\right) \mathrm{ds}\right)\right]=E\left[\min \left[\begin{array}{l}
A_{0} \exp \left(\int_{0}^{T}\left(r_{s}+\lambda\right) \mathrm{ds}\right), \\
H_{0} \exp \left(\int_{0}^{T}\left(\delta_{s}\right) \mathrm{ds}\right)
\end{array}\right]\right] \text { (2) }
$$

Using the previous equation if a certain level of risk premium $\lambda$ is used then solving the above can provide the maximum loan amount $A_{0}$ that can be given; while in reverse if we are given an initial loan amount $A_{0}$, then a fair risk premium $\lambda$ that the lender should use can be determined.

Given the above background to modelling RM, we can return to the main goal of this paper that is to estimate the free rental value of the program using the known parameters. In this study, we use the termination distribution estimated from US data on Reverse Mortgages (Dayananda et al., 2015), which shown to follow a Weibull distribution. The following section develops the models to estimate the free rental for the borrower under the reverse mortgage of the form: (i) lump-sum RM and (ii) tenure RM. The models are then utilized to estimate the free rental values for given plausible parameters used in the industry.

\section{Estimation the Free Rentals - Lump-Sum RM}

We define the following:

$H(t)=$ The value of the house price process at time $\mathrm{t}$, so $H(0)$ is the initial value

$L_{t}$ or $L_{0}=$ The loan value process at time $\mathrm{t}$ and the loan value at $\mathrm{t}=0$ respectively

$k_{1}=$ The premium rate on the loan balance charged after the initial premium $k_{0}$

$H(0)=$ The initial premium cost of the reverse mortgage

$r \quad=$ he risk-free rate assumed constant

$r_{1}=$ The interest rate charged by the lender

$T=$ The termination time of the reverse mortgage policy

$H(T)=$ The Termination value of the house

$U(t) \quad=$ The payoff at time $t:$

$U(T) \quad=$ The payoff at the termination time $T$

$\lambda=$ The fraction of the house value that is not be included in the RM; and

$1-\lambda=$ The fraction of house price value considered for reverse mortgage

Since only a fraction of the house value is involved in the RM, the borrower's payoff from RM at time T may be written as: $U(T)=\left((1-\lambda) H(T)-L_{0} \exp \left\{\left(r_{1}+k_{1}\right) \mathrm{T}\right\}\right)_{+}$, where, $U_{+}=\operatorname{Max}(U, 0)$. The first term on the right is the final value of the house $(H(T))$ while the second term on the right is total debts including the lender's cost of capital and risk insurance rate. The $U(T)$ is only a positive function [(Max $(U, 0)]$; because if the loan increases beyond the $H(T)$ value the liability is accepted by the lender (Not the borrower so this is the lender's risk of loss at Termination).

There are number of costs involved in RM such as insurance cost including other costs to the borrower that can now be incorporated into RM as the Total Costs at time $T$ : 


$$
\begin{aligned}
& \text { Total Costs }=k_{0} H(0) \exp (r T) \\
& +k_{1} \exp (r T)\left\{\exp \left(r_{1}-r+k_{1}\right) T-1\right\} /\left(r_{1}-r+k_{1}\right) .
\end{aligned}
$$

The first term on the right is the total cost the borrower that is a fraction $\left(k_{0}\right)$ of $H(0)$; that is paid upfront as a premium for costs of setting up an RM; the second on the right is the future value of $(T-1)$ payments of the lender's rate of capital $\left(r_{1}\right)$ plus insurance or risk premium of RM from time $t=2 ; k_{1}$ is the rate that accounts for the risk insurance costs of RM over the time of the loan.

The final gain or loss in gross terms to the borrower at time $T$ can be written as:

$$
\text { Loss or Gani }=H(T)-L_{0} \exp (r T)
$$

where, $L_{0}$ is the initial lump sum loan amount from the lender as it grows over time to $T$; allowing for the costs, the net gain/loss to the borrower at termination time $T$ $\left(G_{1}\right)$ may be written as:

$$
\begin{aligned}
& G_{1}=\left((1-\lambda) H(T)-L_{0} \exp \left\{\left(r_{1}+k_{1}\right) T\right\}\right)_{+} \\
& +\lambda H(T)-k_{0} H(0) \exp (r T) \\
& -k_{1} \exp (r T)\left\{\exp \left(\left(r_{1}-r+k_{1}\right) T\right)-1\right\} \\
& /\left(r_{1}-r+k_{1}\right)-\left(H(T)-L_{0} \exp (r T)\right) .
\end{aligned}
$$

Thus the expected risk-neutral present value of the net gain/loss to borrowers:

$$
\begin{aligned}
& E_{Q}\left\{G_{1} e^{-r T}\right\}=E_{Q}\left[e^{-r T}((1-\lambda) H(T)\right. \\
& \left.\left.-L_{0} \exp \left(\left(r_{1}+k_{1}\right) T\right)\right)_{+}\right]+\lambda H(0) \\
& -k_{0} H(0)-k_{1}\left\{\exp \left(\left(r_{1}-r+k_{1}\right) T\right)-1\right\} /\left(r_{1}-r+k_{1}\right) \\
& -H(0)+L_{0} .
\end{aligned}
$$

We assume that the house price process $H(t)$ has a geometric Brownian motion with mean and variance $\mu$ and $\sigma^{2}$ respectively. Then using Black and Scholes (1973), the first component of (5) reduces to:

$$
\begin{aligned}
& E_{Q}\left[\left((1-\lambda) H(T)-L_{0} \exp \left\{\left(\mathrm{r}_{1}+k_{1}\right) T\right\}\right)_{+}\right. \\
& =(1-\lambda)\left\{H(0) \Phi\left(\mathrm{d}_{1}\right)-\exp (-r T) K_{1}(T) \Phi\left(d_{2}\right)\right\}
\end{aligned}
$$

with $\Phi$ as the cumulative distribution function for the standard normal distribution:

$$
\begin{aligned}
& d_{1}=\left\{\ln \left(H(0) / \mathrm{K}_{1}(T)\right)+\left(r+0.5 \sigma^{2}\right) T\right\} / \sigma \sqrt{T}, \\
& K_{1}(T)=L_{0} \exp \left(\left(r_{1}+k_{1}\right) T\right) /(1-\lambda) \\
& \text { and } d_{2}=d_{1}-\sigma \sqrt{T} .
\end{aligned}
$$

Thus we can express the relation in (5) for given $\mathrm{T}$ as:

$$
\begin{aligned}
& E\left\{G_{1} e^{-r T} T\right\} \\
& E\left\{G e+\lambda H(0)-k_{0} H(0)\right. \\
& -k_{1}\left\{\exp \left(\left(r_{1}-r+k_{1}\right) T\right)-1\right\} /\left(r_{1}-r+k_{1}\right) \\
& -H(0)+L_{0}
\end{aligned}
$$

The expression in (5) provides the borrower, provided it is again, the expected present value of the rental free residence. Let $R_{1}=$ Rental rate to the borrower corresponding to the reverse mortgage policy. Then the present value of the rental for the period $T$ :

$$
R_{1} \bar{a}_{T}=R\left(1-e^{-r_{2} T}\right) / r_{2}
$$

where, $r_{2}=$ Interest rate applicable to rental policies in the period $(0, T)$.

Hence:

$E_{Q}\left\{G e^{-r T}\right\}=E\left\{R\left(1-e^{-r_{2} T}\right) / r_{2}\right\}$.

The relation in (8) establishes a mechanism to evaluate the free rental rate associated with the reverse mortgage policy. It is given by:

$$
R_{1}=\frac{r_{2} E\left\{G e^{-r T}\right\}}{E\left\{1-e^{-r_{2} T}\right\}} .
$$

The distribution for the termination time $T$ was found to be Weibull with density $f(t)$, Dayananda et al. (2016), unpublished and is given by:

$$
f(t)=\alpha t^{\alpha-1} \exp \left\{-(t / \beta)^{\alpha}\right\} / \beta^{\alpha} .
$$

Thus the expectations needed in (10) reduce to:

$E\left\{\mathrm{G}_{1} \mathrm{e}^{-r T}\right\}=\int_{0}^{105-x} G_{1} e^{-r t} f_{1}(t) d t$

and

$E\left\{1-e^{-r_{2} T}\right\}=\int_{0}^{105-x}\left(1-e^{-r_{2} t}\right) f_{1}(t) d t$

where, $f_{1}(t)=f(t) / \int_{0}^{105-x} f(t) d t$ and $\mathrm{x}$ is the age of the reverse mortgage borrower and 105 is the extreme age in life. 


\section{Case 2 Tenure: Regular Payment to the Reverse Mortgage Owner}

Let $Y$ be the continuous payment to the borrower whose age is $x$ under tenure policy:

$$
Y \bar{a}_{\overline{105-x}}=(1-\lambda) H(0)
$$

assuming that the reverse mortgage is based on total house equity value.

Thus at termination time $T$, the value of the payments is accumulated to:

$Y_{\bar{T}}$ at rate $r_{1}+k_{1}$

Now the components for the computation of the net value to the borrower at termination time $T$ are:

(1) Payoff and the residual home value $\left((1-\lambda) H(T)-Y s_{T}\right)_{+}+\lambda H(T)$,

(2) Insurance cost:

$$
k_{0} H(0)+k_{1} \frac{Y e^{\left(r_{1}+k_{1}\right) T}}{\left(r_{1}+k_{1}\right)}\left[\begin{array}{l}
\left\{\frac{1}{r}+\frac{e^{-\left(r+k_{1}\right) T}}{\left(r-r+k_{1}\right)}\right\} \\
\left.-\left\{\frac{1}{r}+\frac{1}{\left(\mathrm{r}_{1}-r+k_{1}\right)}\right\} e^{-r T}\right\}
\end{array}\right],
$$

(3) Termination proceeds $H(T)+Y \bar{a}_{T} e^{r T}$.

Therefore the total net benefit to the borrower at termination time $T$ is:

$$
\begin{aligned}
& G_{2}=\left((1-\lambda) H(T)-Y \bar{s}_{T}\right)_{+}-(1-\lambda) H(T)-k_{0} H(0) e^{r T}- \\
& k_{1} \frac{Y e^{\left(r+k_{1}\right) T}}{\left(r_{1}+k_{1}\right)}\left[\left\{\frac{1}{r}+\frac{e^{-\left(r_{1}+k_{1}\right) T}}{(r-r+k)}\right\}-\left\{\frac{1}{r}+\frac{1}{\left(r-r+k_{1}\right)}\right\} e^{r T}\right]
\end{aligned}
$$

Thus the present value of the net borrower benefit is:

$$
\begin{aligned}
& E_{Q}\left(G_{2} e^{-r T}\right)=E_{Q}\left[\mathrm{e}^{-r T}(((1-\lambda)\right. \\
& \left.\left.H(T)-Y S_{\bar{T}}\right)_{+}\right)-(1-\lambda) H(0)-k_{0} H(0)- \\
& k_{1} \frac{Y e^{\left(r+k_{1}-\mathrm{r}\right) T}}{\left(r_{1}+k_{1}\right)}\left[\left\{\frac{1}{r}+\frac{e^{-\left(r_{1}+k_{1}\right) T}}{(r-r+k)}\right\}-\left\{\frac{1}{r}+\frac{1}{\left(r-r+k_{1}\right)}\right\} e^{r T}\right]
\end{aligned}
$$

Now following the same argument as in (9), the continuous free rental provided by the reverse mortgage is:

$$
R=\frac{r_{2} E\left[G_{2} e^{-r T}\right]}{\mathrm{E}\left[\left(1-e^{-r_{2} T}\right)\right]} .
$$

\section{Discussion of Numerical Results}

The annual rental calculations provided in the figures and tables in this section are based on the formulas presented in the previous section. The integrations were performed numerically and the results are presented in the Tables 1-4. The annual rental charge allowed using the formula of various set of couples was investigated for three different levels of risk $(\sigma)$; namely, $0.1,0.2$ and 0.3 . The differing initial house valuations were also taken into account in that the real estate concerning average to upper middle level of dwellings were considered in the modelling; namely, 200K, 300K, $400 \mathrm{~K}, 500 \mathrm{~K}$ and $600 \mathrm{~K}$. Such values are line with those in the house valuation literature for the most Australian cities (see: https://www.ahuri.edu.au/).

A number of constants were used in the modelling such as Dayananda (2015) values of $k_{0}, k_{1}, r, r_{1}$ and $r_{2}$. The following constants were used to determine the parallel annual rental charges: namely:

$$
k_{0}=0.02, k_{1}=0.005, r=0.02, r_{1}=0.035, r_{2}=0.02
$$

Similar tables can be developed to each age group for each risk value of sigma. Tables 1-3 above show various scenarios/cases of aged couples retiring but choosing to stay and live in their homes (with homes values from the range of $200 \mathrm{~K}$ to $600 \mathrm{~K}$ ) as if they were in fact renting it from the bank; that is, the given the couples chose to take a reverse mortgage condition with institutions such as a bank that offers the same. The initial housing values being in line with the reverse mortgage values at the initial point; clearly, these are assessed by valuations of houses conducted by those institutions/companies that sell mortgage products such as the banks. Table 4 summarizes other tables of age couple but using a middling risk factor of 0.2 for sigma.

The Fig. 1 shows various groups plotted with Series 1 referring to the 65,65 couple to Series 4: 75, 75 couple respectively. The first four columns of Table 3 are plotted and compared marginally in Fig 3. Series 1 is drawn for the couple aged 65,65 . The yearly rental ranges from 6313 to 18939 depending on the valuation of their house; varying from $200 \mathrm{~K}$ to $600 \mathrm{~K}$ respectively. This group would on the whole involve a somewhat higher risk to the bankers than others with the possibility of being healthier and living longer, thus renting for longer period so to say. We note a restriction in amount that is available for them column wise in Table 3 when compared to other columns. The Series 2 refers to the 65 , 75 aged couple; while Series 3 refers to 65,85 group; and finally the Series 4 is drawn for the 75,85 group. A similar pattern is noted in each condition. 
Interestingly, the most risky for the banks will be the higher aged couples but the amount of time to end point of their lives may be much less. So the total risk of paying out large amounts is less; and also therefore the rental amount yearly calculated will tend to be more than earlier year couples accordingly. The virtual rental yearly amounts is higher for the given house values for the age 75,85 and 85,85 couples when compared to others; others of lower age groups even when we compare the higher values housing $(H(0)$ in the first column of Table 3); when allowing for the house valuations and examining marginally again, we see across rows, the values are increasing Fig. 3 and Table 3.
Figures 1, 2 and 3, the $\mathrm{Y}$ axis is the rental calculated in dollars yearly using our modelling procedure and it is noted that all are rising for all groups as ages of couples increase across rows of Table 3 (Fig. 1-3). The amounts are also increasing column wise since the bank housing valuation increases with higher real market values of homes (Fig. 1 and 2). In the end this may suggest that it is not appropriate to undertake a RM contract at higher age groups, for one can rent at lower levels by obtaining a rental condition in the market place for a similar house. However this analysis is presented and discussed later when the housing and rental market conditions are further analysed.

Table 1: Annual rental charge (\$) for various initial house values - couples (Ages pair 65, 65)

\begin{tabular}{lccc}
\hline $\mathrm{H}(0)$ & $\sigma=0.1$ & $\sigma=0.2$ & $\sigma=0.3$ \\
\hline 200000 & 6318 & 6313 & 6106 \\
300000 & 9477 & 9470 & 9159 \\
400000 & 12636 & 12626 & 12212 \\
500000 & 15796 & 15783 & 15265 \\
600000 & 18955 & 18939 & 18313 \\
\hline
\end{tabular}

Table 2: Annual rental charge (\$) for various initial house values - couples (Ages pair 65, 75)

\begin{tabular}{lccr}
\hline $\mathrm{H}(0)$ & $\sigma=0.1$ & $\sigma=0.2$ & $\sigma=0.3$ \\
\hline 200000 & 6784 & 6780 & 6607 \\
300000 & 10176 & 10170 & 9101 \\
400000 & 13568 & 13561 & 13204 \\
500000 & 16960 & 16951 & 16508 \\
600000 & 20353 & 20341 & 19822 \\
\hline
\end{tabular}

Table 3: Annual rental charge (\$) for various initial house values - couples (Ages pair 65, 85)

\begin{tabular}{llll}
\hline $\mathrm{H}(0)$ & $\sigma=0.1$ & $\sigma=0.2$ & $\sigma=0.3$ \\
\hline 200000 & 7179 & 7175 & 7009 \\
300000 & 10769 & 10763 & 10513 \\
400000 & 14358 & 14351 & 14018 \\
500000 & 17948 & 17938 & 17522 \\
600000 & 21538 & 21526 & 21027 \\
\hline
\end{tabular}

Table 4: Annual Rental charge (\$) across couples of different age groups when $\sigma=0.2$

\begin{tabular}{|c|c|c|c|c|c|c|}
\hline \multirow[b]{2}{*}{$\mathrm{H}(0)$} & \multicolumn{6}{|c|}{ Aged couple } \\
\hline & 65,65 & 65,75 & 65,85 & 75,85 & 75,75 & 85,85 \\
\hline 200000 & 6313 & 6780 & 7175 & 8057 & 7379 & 9397 \\
\hline 300000 & 9470 & 10170 & 10763 & 12075 & 11069 & 14089 \\
\hline 400000 & 12626 & 13561 & 14361 & 16100 & 14758 & 18785 \\
\hline 500000 & 15783 & 16957 & 17938 & 20125 & 18448 & 23481 \\
\hline 600000 & 18939 & 20341 & 21526 & 24150 & 22138 & 28177 \\
\hline
\end{tabular}

Table 4: Annual Rental (\$) with increasing ages of couples and increases in housing valuations (\$)

\begin{tabular}{lllllll}
\hline $\mathrm{H}(0) /$ Age & 65,65 & 65,75 & 65,85 & 75,75 & 75,85 & 85,85 \\
\hline 200000 & 6313 & 6780 & 7175 & 7379 & 8057 & 9397 \\
300000 & 9470 & 10170 & 10763 & 11069 & 12075 & 14089 \\
400000 & 12626 & 13561 & 14361 & 14758 & 16100 & 18785 \\
500000 & 15783 & 16957 & 17938 & 18448 & 20125 & 23481 \\
600000 & 18939 & 20341 & 21526 & 22138 & 24150 & 28177 \\
\hline
\end{tabular}


Gurudeo Anand Tularam and Ali Abdullah Al Ibrahim / Journal of Mathematics and Statistics 2018, 14 (1): 40.51

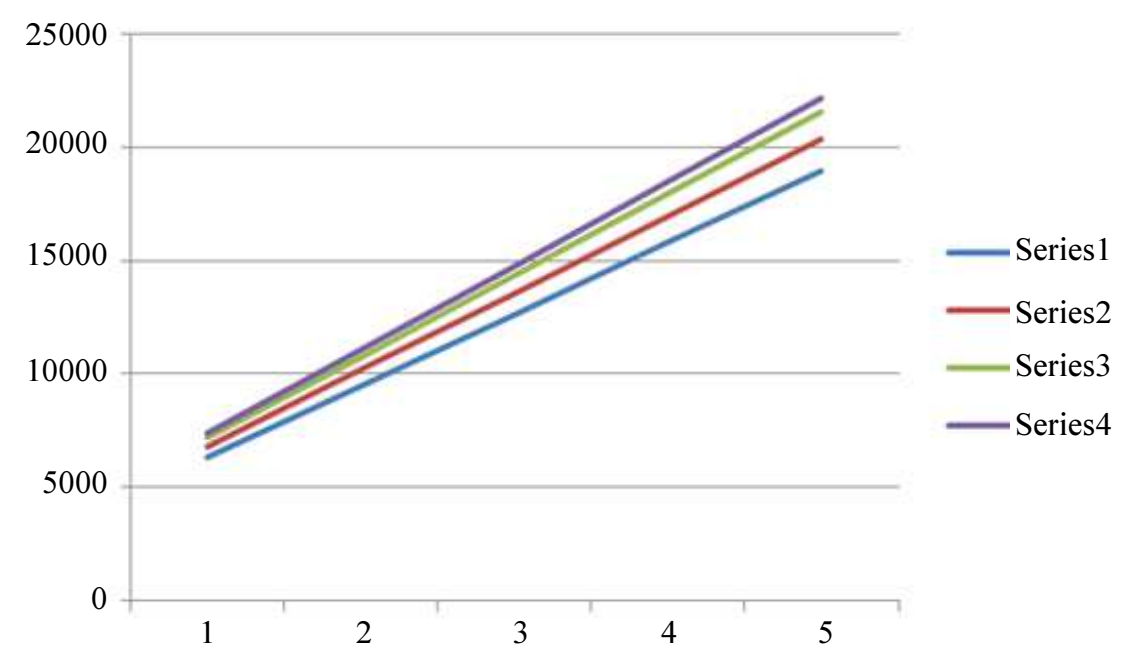

Fig. 1: Plots of columns of Table 3

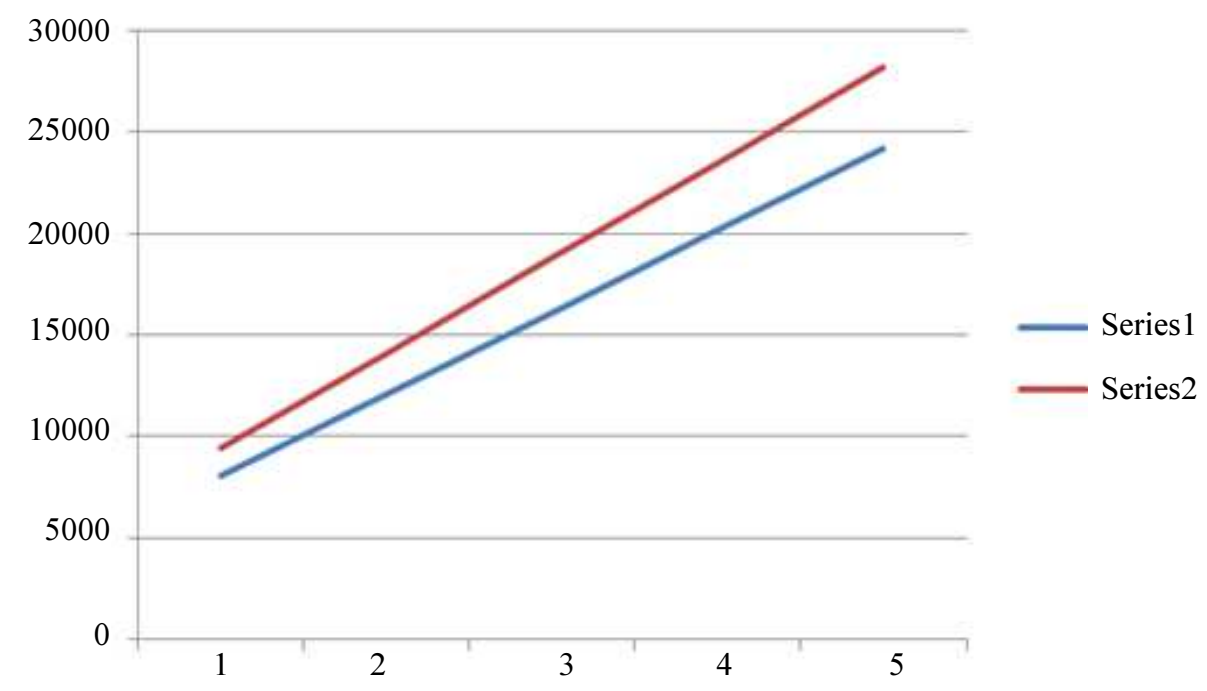

Fig. 2: Plot of 75, 85 and 85,85 columns of Table 3

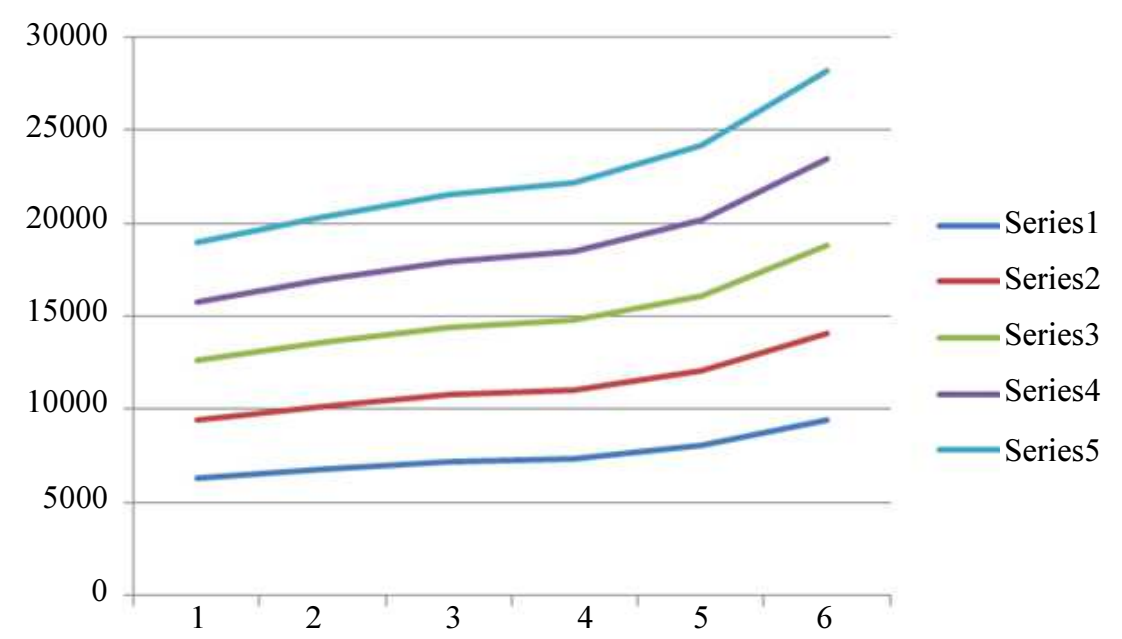

Fig. 3: Annual rental marginal across age groups plot of rows of Table 3 
Annual Rental (Y axis) with volatility $(\sigma=0.2)$ when $\mathrm{H}(0)$

60 varies $(\times \$ 1000) \mathrm{H}(0)$ is on the $\mathrm{X}$ axis

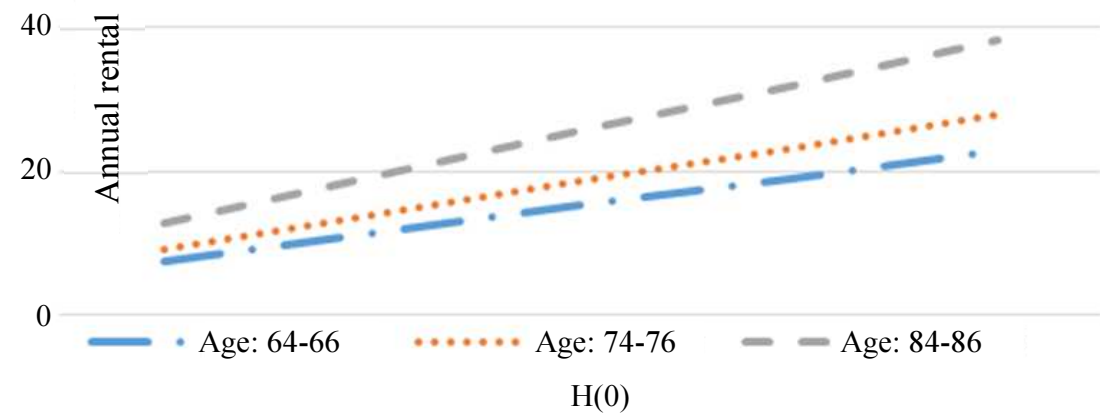

Fig. 4: Annual rental summary of all couple pairs analysed

We may rearrange Table 3 in way that is increasing age combinations by swapping the 75,85 and 75,75 columns (in Table 3 ) and such a table may show a better picture in that we may compare the increases along rows and columns with increasing age more appropriately as shown in Table 4.

Figure 3 shows the annual rental calculations based on modelling increasing across and down the Table 4 in approximately a linear pattern initially with lower aged couples; and then at higher home prices and higher aged couples, the rental amount yearly becomes a non-linear and approaches a quadratic relationship.

In the Fig. 3 and 4 above, show a better summary of the earlier analysis is presented. There seems to be a particular trend line for the age group at which the couples retire. In this case, the $\mathrm{x}$ axis is the initial point real estate valuation of the home $(H(0))$ owned by a possible retiree. In most Australian cities the Bank valuations of houses range from $200 \mathrm{~K}$ to $600 \mathrm{~K}$ for lower to the middle value range or group in the housing market. In this analysis, the homes valued under $200 \mathrm{~K}$ are not considered as these would not be suitable for the comparable rental housing needed for retirement of aged couples considered here; since it is assumed that the retirees own their own home in the analyses in this study. There is of course the condition of a single person condition as well but this may indeed become a different scenario given a single person may be able to stay in a unit of one bedroom for example and the valuation may indeed be less than $200 \mathrm{~K}$ but this is an unlikely situation in the current housing market in Australia.

\section{A Comparative Analysis of Renting in Australian Major Cities}

There is much data in the literature regarding the Australian housing market and much of this data is available now on the web (https://www.ahuri.edu.au/).
Using real estate.com web site data (and others such as https://www.reiv.com.au/property-data/medianprices/median-prices-in-regional-victoria), we can calculate various rental housing statistics for major cities in Australia. For example, for the greater Melbourne the available homes/units for rent is about 2146 properties. The most expensive rental property is around $\$ 2500$ per week ( $\$ 130000$ yearly); and the least expensive rental is $\$ 330$ per week ( $\$ 17160$ yearly for a 1 bedroom unit). For greater Brisbane, the availability is around 7800; the most expensive rental is $\$ 2950$ per week ( $\$ 153400$ yearly); and the least expensive rental is $\$ 110$ per week ( $\$ 5720$ yearly for room - house share). In the case of greater Perth the availability for rent properties is around 12,785 ; with the most expensive rental is $\$ 3000$ per week $(\$ 156000$ yearly); and the least expensive rental is noted to be $\$ 70$ per week ( $\$ 3640$ for room - house share)

In greater Hobart there are 265 properties available for rental with the most expensive being around $\$ 1000$ per week ( $\$ 52000$ yearly); the least expensive rental is $\$ 130$ per week ( $\$ 6760$ yearly for a 1 bed studio). In greater Darwin there are around 965 properties available for rent with the most expensive rental around $\$ 2000$ per week ( $\$ 104000$ yearly); and the least expensive rental being around $\$ 179$ per week ( $\$ 9308$ for a room in a house share condition). The lower rental availability (low supply) shows why the rents are rising in Hobart and also similarly but oppositely, with the large availability or supply is one of the reasons why Perth rental is lower.

The above data is only for 2016 and is the values are always changing, so the retirees may consider moving to different parts of Australia to retire for their benefit; if of course the market rental is much cheaper than the option of a RM contract. If a person owns their own home without mortgage when considering retirement and if the option that is favored by modelling is the rental rather than reverse mortgage then the person needs to consider 
where to live for optimal financial condition or indeed optimal "choice" or "happiness" condition) and these two interests may help in the decision to choose an RM over market rentals in choice living locations. The information and statistics regarding the market rentals in this regard are available on various websites such as: https://www.reiv.com.au/property-data/rental-

data/vacancy-rates.

Clearly, there is a range of values of rental prices in Australia and the rental values are usually dependent on locations such as whether the rental are units or houses and whether they are close to near or indeed in the city boundaries; or in the greater regions of cities; or whether in fact the rental are in regional areas of the states of Australia. The choice of retirement locations will play a major part in deciding whether a retiree may sell their home or move to other locations of choice, in which case reverse mortgage may not be as useful to them as to others who wish to remain in their homes for their retirements.

However, depending on conditions of a contract it may still be possible to move to other areas or locations of choice such as coastal regions and still engage in a reverse mortgage contract by allowing their off springs or indeed younger families to live in the homes during the period of the mortgage. This may be able to facilitate the present crises of housing for the younger generation. The problems of young buyers not being able to afford and thus not engage in the housing market is a major one for Australia. That is, it may be that taking a reverse mortgage may be not only beneficial to the retiree but also positively benefit the present housing conditions of supply etc., where in the main the young buyers are not able to buy into the 2016-17 market conditions.

Table 5 shows a summary of weekly rental for most major cities in Australia. The change is also given per year so some simplistic predictions can be made regarding the cities and trends in their rental prices.

The information in Table 5 is highly reliable since the Core Logic group argue that it is indeed "the largest provider of property information, analytics and propertyrelated risk management services in Australia and New Zealand...." (see https:/www.corelogic.com.au/). The range of rental in major cities is $\$ 359$ to $\$ 593$ per week in 2016 ; that translates to $\$ 18668$ and $\$ 30836$ yearly respectively. The average of all Australian cities combined is $\$ 481$ per week, which translates to $\$ 25012$ yearly.

The rental data gathered from the main cities suggest that Sydney is most expensive but there are equally areas that are similar to average rentals in other cities so in this study the rental data from all Sydney suburbs is analysed first and compared with the rentals generated from the our predicted reverse mortgage rental amounts using our mathematical model. This is because we need to examine the most populated market to determine whether it is reasonable to engage in $\mathrm{RM}$; in the high market rental conditions. The RM will also be useful for all retirees in other less expensive rental markets because it could possibly be that they may sell their house and meet the lower market rental conditions but with our results and Australian housing rental data this seems unlikely (Fig. 5).

Using the median rental in Sydney the maximum yearly amount in dollars can be said to be around 36400 dollars or $\$ 700 /$ week (Fig. 6). It is noted that the reverse mortgage modelled rental calculated in Tables 1-3 earlier shows that the prospective retirees may be much better off using their homes as a basis for rental consideration instead and thus initiate a RM process; taking a rental amount from the banks (as salary) who offer the reverse mortgage in accord to the valuations of the homes of retirees varying from $200 \mathrm{k}$ to $600 \mathrm{k}$ (Table 3 ).

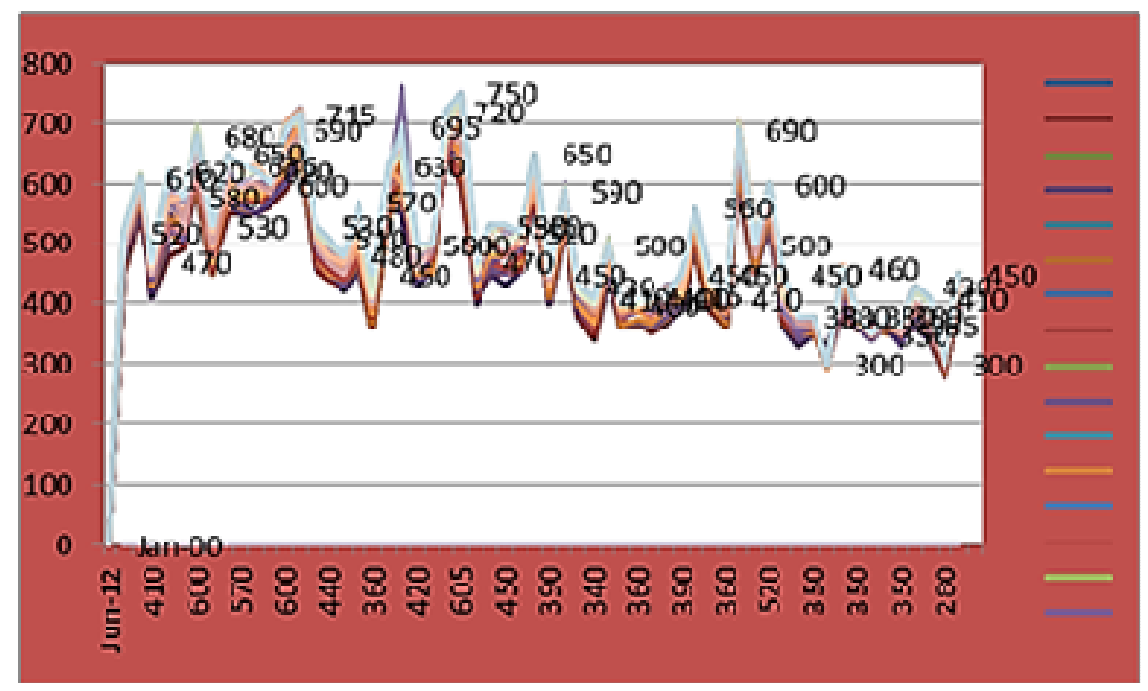

Fig. 5: Range of rental costs per week in Sydney (Houses and Units-Average rental values) 


\section{Bedroom Rental Scenario - Sydney}

In Fig. 3 the $\mathrm{x}$ axis represents suburbs, where the values of 1 to 4 represent the inner city suburbs where in most cases the retirees will not prefer on average preference of a location for example. The outer suburbs are greater numbers from 4 and could represent a more realistic market rental option for a 2-Bedroom Unit. According to the amounts shown in Fig. 7, we can conclude that a 2 bedroom unit has a maximum rental of around 750 dollars per week (at the most expensive end), while the minimum cost is around 250 per week (at the least expensive end of the market). In the case of $700 \mathrm{a}$ week, the yearly rental amount amounts to 39000 dollars; while the minimum is around 13000 dollars per year. Now if we compare this to the rental amounts yearly using the Tables presented earlier.

In the first column of Table 4 , we can conclude that fir a 65,65 couple it may be better to undertake RM in the case of up to homes valued around $400 \mathrm{~K}$ or less; but with home values greater than this it may be not as good for the market rental may be a cheaper option. For a 65 , 75 couple, it may be an option to undertake market rental if their home is less than $400 \mathrm{~K}$ or thereabouts (and less). For the 65,85 couple, the RM would be better if their home was valued around $300 \mathrm{~K}$ or less. For a 75, 75 (and a 75, 85 couple), the RM would be a better option if their home was valued around $300 \mathrm{~K}$ less; and for an 85,85 couple, the RM option is only appropriate if the home value is around $200 \mathrm{~K}$ or less.

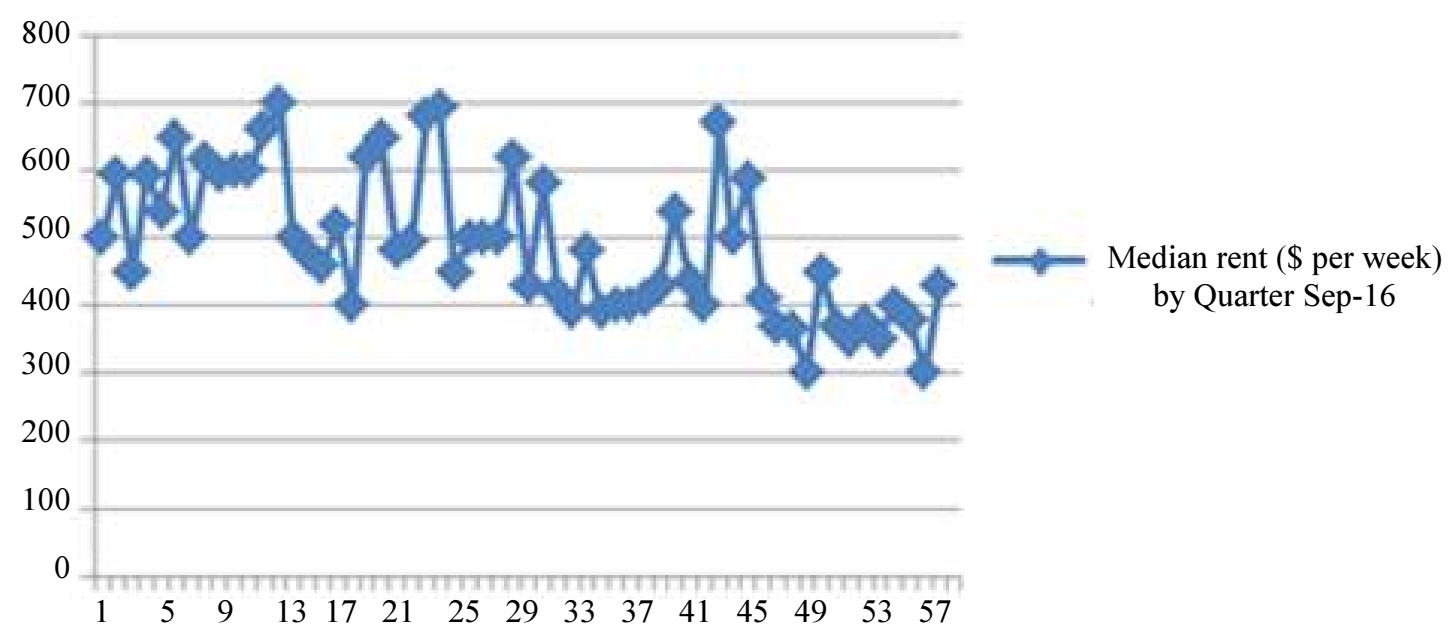

Fig. 6: Median Rental per week across all suburbs of Sydney (Houses and Units)

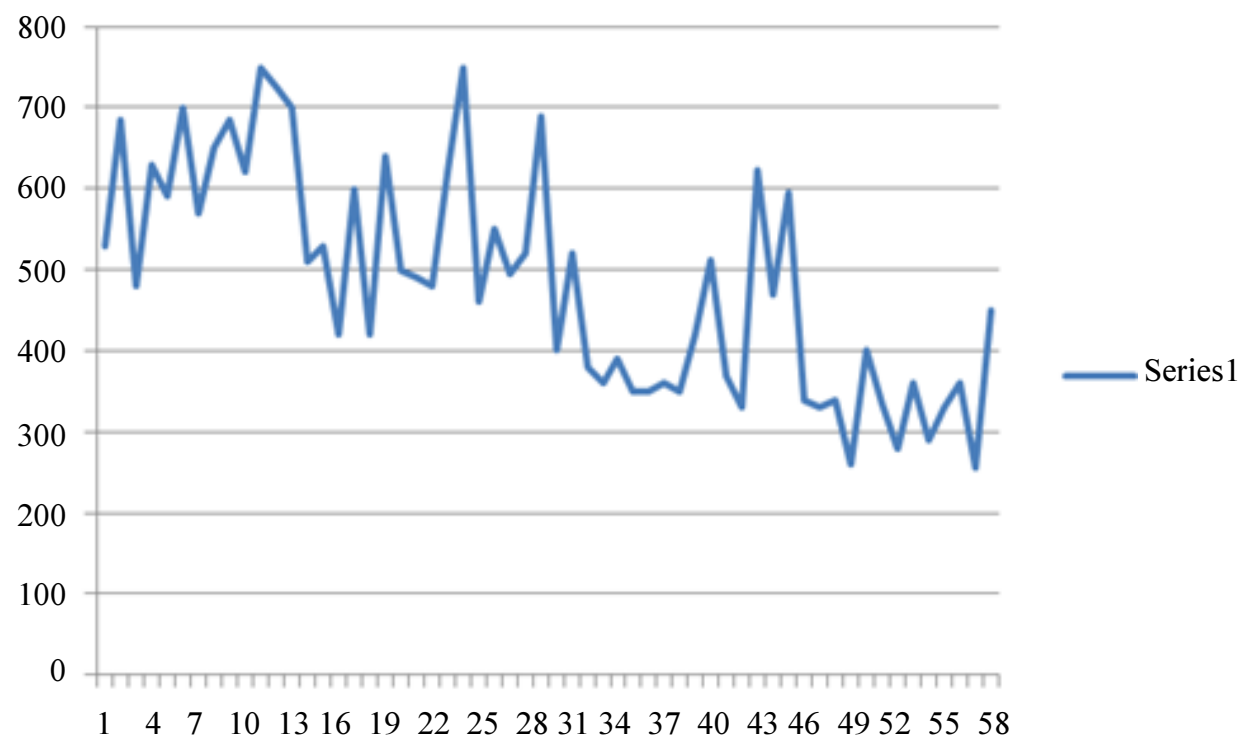

Fig. 7: Rental of 2-bedroom units in Sydney by suburbs (1-4 inner city; final average of NSW) 
Table 5: House rental prices in major cities in Australia as at August 2016

\begin{tabular}{lll}
\hline City & Average weekly rent & \% change 12 months \\
\hline Sydney & $\$ 593$ & 0.2 \\
Melbourne & $\$ 458$ & +2.4 \\
Brisbance & $\$ 427$ & -1.1 \\
Perth & $\$ 419$ & -9.4 \\
Adelaide & $\$ 364$ & -0.3 \\
Canberra & $\$ 504$ & +2.6 \\
Hobart & $\$ 359$ & +6.8 \\
Darwin & $\$ 463$ & -14.1 \\
Combined capitals & $\$ 481$ & -0.5 \\
\hline
\end{tabular}

\section{Discussion}

Table 4 shows that for the 65,65 age couples, it is most probably better to remain in the home and for retiring purpose proceed to invest in a reverse mortgage since the amount of rental yearly for their home is much lower than that available for a similar in the market for retirement purposes. The rental price for a 2-Bedroom Unit or a similar of real estate value house of around $200 \mathrm{~K}-400 \mathrm{~K}$, is around 300 a week (as a minimum rental), which translates to $\$ 15600$ yearly. This amount is higher yearly if the couples (choose to rent in a reasonable home. In most cases, the rental is around $\$ 450$ a week and this translates to $\$ 23400$ yearly for a modest home or unit possibly away from the central city. When compared to even a $600 \mathrm{~K}$ value, the rental is still lower than the current rental market for a downsized 2Bedroom unit or a 3 Bedroom home at least $30 \mathrm{~km}$ from the city centre for example.

\section{Melbourne House Rental Scenario}

Using the above figures in Table 6 we may also suggest yearly averages of around \$22646 in metro area and $\$ 15860$ in regional areas for housing rental. Based on regional rentals and using the second major Australian city housing rental figures, we also conclude that a 65,65 couple with home value of $500 \mathrm{~K}$ or less could choose RM instead of seeking market rentals; while a 65,75 couple with a home value of $400 \mathrm{~K}$ or less may also choose to engage in RM; similarly, a 65, 85 couple could engage in RM if they have a house worth $400 \mathrm{~K}$ or less. The 75,85 aged couple should choose an $\mathrm{RM}$ if they own a home worth $300 \mathrm{~K}$ or less; while the 75,75 aged couples could choose RM if their home is worth $400 \mathrm{~K}$ or less; and finally, the 85,85 group could choose RM is their home is worth $300 \mathrm{~K}$ or less.

In the case of choosing metro rental we can also make predictions of which age group couples should choose to remain in their property and engage in RM for their retirements. For example, in the case of Melbourne city, apart from 75, 85 and 85, 85 aged couples all the rest could choose to engage in RM if their homes were valued at $600 \mathrm{~K}$ or less. In other words, it would be worth their while to be engaged in a RM contract and remain in their homes during retirement because in essence they will be paying less rental amounts when compared to market conditions.
Table 6: Median house rental (per week) in Melbourne

\begin{tabular}{ll}
\hline Melbourne & Median Rent (Houses) \\
\hline METRO & $\$ 435.5$ \\
REGIONAL & $\$ 305$ \\
\hline
\end{tabular}

\section{Summary and Conclusion}

The aim of this paper was to compare the rental market conditions in retirement with an RM contract that involves a retiree's home and its valuation. It is noted that the current rental market conditions is to be examined thoroughly before any engagement in RM is to be instituted. The rental value per week for 1, 2Bedroom Units and 3 or more Bedroom homes are to study in some depth. The availability of rental housing should also be studied to determine whether it is indeed possible to obtain secure longer term rental housing for the retired persons. In this study only a certain group has been investigated and further work is necessary if $\mathrm{RM}$ is to be a major contract that retired persons may engage in thus achieving a better quality of life after retirement given the many years of service couples have given to their country.

The human nature of unknown, or not knowing what may be involved in terms of details within a reverse mortgage contract including many other complexities that can be involved in releasing one's ownership of to the reverse mortgage contract has meant that many countries are now lagging behind the more advanced countries such as the US, Singapore and others in delving into the reverse mortgage market focusing on retired persons. This is clearly noted in the major lack of information that is able in Australia for example. There is a clear lack of discussion of RM's amongst the markets and institutions operators such as credit companies and banks for example. There is indeed hardly if any advertising of RM in the major forms of the media. It is true that RM is less strongly pushed even in the usual transactions in banks when often products such as insurance and the like are loudly announced often as you enter many banks; mainly pushed by their tellers on site. The lack of engagement in Australia is a two way story in that the less than usual interest of retiree's on $\mathrm{RM}$ is met by the banks very low level of advertising of the same. The lack of information has created a lack of trust in RM; the thought of letting someone else own 
apart of one's home towards the later part of one's life in some manner is not well accepted or understood given the retiree's home is mostly a mortgage free asset.

The modelling and analyses conducted in this study shows that the return in terms of rental is well in competition with the existing rental market in Australia and in particular when using the largest city data from Sydney and other rental markets.

\section{Acknowledgement}

We would like to thank Pro Dayananda W Palahela from Uni of St Thomas for his help and guidance in this paper. We also thank EFRI.

\section{Author Contribution}

Gurudeo Anand Tularam: 60\%

Ali Abdullah Al Ibrahim: 40\%

\section{Ethics}

This article is original and contains unpublished material. The corresponding author confirms that all of the other authors have read and approved the manuscript and there are no ethical issues involved.

\section{References}

Alai, D.H., H. Chen, D. Cho, K. Hanewald and M. Sherris, 2014. Developing equity release markets: Risk analysis for reverse mortgages and home reversions. North Am. Actuarial J., 18: 217-241.

Black, F. and M.S. Scholes, 1973. The pricing of options and corporate liabilities. J. Political Economy. 81: 632-656.

Bridge, C., T. Adams, P. Phibbs, M.R. Mathews and H.L. Kendig, 2010. Reverse mortgages and older people: growth factors and implications for retirement decisions. Australian Housing and Urban Research Institute UNSW-UWS Research Centre: AHURI Final Report No. 146.

Chen, H., S.H. Cox and S.S. Wang, 2010. Is the home equity conversion program in United States sustainable? Evidence from pricing mortgage insurance premiums and non-recourse provisions using the conditional Escher transform. Insurance Math. Econom., 46: 371-384.

Cho, D., K. Hanewald and M. Sherris, 2013. Risk Management and payout design of reverse mortgages. Proceedings of the Actuaries Institute Actuaries Summit Held During, May 20-21, Actuaries Institute, Sydney, Australia, pp: 1-33.

Dayananda, B., Gray, S., Pike, D. and Webb, J.K., 2016. Communal nesting under climate change: fitness consequences of higher incubation temperatures for a nocturnal lizard. Global Change Biology, 22: 2405-2414.
Dayananda, D., V.R. Sarva, S.V. Prasad, J. Arunachalam and P. Parameswaran et al., 2015. Synthesis of $\mathrm{MgO}$ nanoparticle loaded mesoporous Al $2 \mathrm{O} 3$ and its defluoridation study. Applied Surface Sci., 329: 1-10.

Edward, S.L., J.C. Enriquez and T.R. DiVenti, 2007. Home equity conversion mortgage terminations: Information to enhance the developing secondary market. Cityscape, 9: 5-45.

Firman, J.P., 2015. The official reverse mortgage consumer booklet approved. U.S. Department of Housing and Urban Development, VA: National Council on AgingUse.

Hopf, C. and G.A. Tularam, 2014. A mathematical analysis of the inclusion of institutional betting funds into stock market: The case of technical and fundamental payoff models in horserace betting. J. Math. Stat., 10: 390-400.

Liang, W., E.A. Valdez and J. Piggott, 2008. Securitization of longevity risk in reverse mortgages. North Am. Actuarial J., 12: 345-371.

Maestas, N. and J. Zissimopoulos, 2010. How longer work lives ease the crunch of population aging. J. Econom. Perspectives, 24: 139-160.

Nakajima, M. and I.A. Telyukova, 2014a. Housing and saving in retirement across countries.

Nakajima, M. and I.A. Telyukova, 2014b. Reverse mortgage loans: A quantitative analysis. J. Finance, 72: 911-950. DOI: 10.1111/jofi.12489

Nakajima, M., 2012. Everything you always wanted to know about reverse mortgages but were afraid to ask. Bus. Rev., Q1: 19-31.

Nance, C., 2016. Unlocking housing wealth-options to meet retirement needs. Institute of Actuaries of Australia.

Reed, R.G., 2009. The increasing use of reverse mortgages by older households. Proceedings of the 15th Annual Pacific Rim Real Estate Society, Jan. 18-21, Sydney, Australia, pp: 1-18.

Thomas, D., 2014a. Can 'high costs' justify weak demand for the home equity conversion mortgage? University British Columbia.

Thomas, D., 2014b. Reverse mortgage demographics and collateral performance. University British Columbia.

Tularam, G.A., 2013. Mathematics in finance and economics: Importance of teaching higher order mathematical thinking skills in finance. J. Bus. Educ. Scholarship Teaching, 7: 43-73.

Warshawsky, M.J. and T. Zohrabyan, 2016. Retire on the house: The use of reverse mortgages to enhance retirement security literature review, current market terms, empirical analysis and simulations, international comparisons and Public Policy Ideas. MIT Center Finance Policy.

Warshawsky, M.J., 2017. Retire on the house the possible use of reverse mortgages to enhance retirement securit. Mercatus Working Paper. 